\title{
Hirschsprung's disease: genetic mutations in mice and men
}

\section{Summary}

Hirschsprung's disease is a neuronal dysplasia of the hindgut, characterised by a loss of neurones, which affects about 1 in 5000 live births. ${ }^{1}$ Genetic factors have been implicated in the aetiology of this disease in about $20 \%$ of cases and a dominant pattern of inheritance has been revealed in several families. ${ }^{2}{ }^{3}$ The pathogenesis of the aganglionosis is often attributed to a failure of migration of neural crest cells, although this has not been proven.

Recently, mutations in a developmentally regulated receptor tyrosine kinase gene, ret, and mutations in the endothelin receptor-B gene (ENDR-B) have both been linked to familial Hirschsprung's disease in humans. ${ }^{4-6}$ Moreover, certain mutant mouse strains-namely piebald lethal and lethal spotted-exhibit striking similarities to the human condition. The mutation which gives rise to piebald lethal has now been found to be in the ENDR-B gene, ${ }^{7}$ and the mutation associated with lethal spotted occurs in the gene for endothelin-3 (ET-3), a ligand for ENDR-B. ${ }^{8}$

Two transgenic mouse lines have been developed which also reflect the human disease: ret- $k^{-}$, which has a loss of function mutation of the ret gene, ${ }^{9}$ and ENDR-B null. ${ }^{10}$ In addition, the introduction of a Lac- $Z$ reporter gene into neural crest cells of aganglionic mice has made it possible to study directly the fate of enteric neuroblasts which are affected by "Hirschsprung's-like" mutations. ${ }^{11}$ Here, we review the possible roles of RET and endothelin in the normal development of the enteric nervous system, and the significance of their mutated forms in the pathogenesis of familial aganglionosis.

This review focuses on recent advances in our understanding of the genetic basis of the lesions which have been implicated in congenital forms of Hirschsprung's disease. Disruption of these genes in the mouse, either by transgenic "knockout" approaches or in mutant mouse lines, offers the prospect of greater understanding of both the cellular and developmental bases of the human disease.

\section{The enteric nervous system}

In 1921, Langley described the enteric nervous system (ENS) as a distinct division of the autonomic nervous system, relatively independent of the CNS. ${ }^{12}$ Today, the ENS is recognised as a highly complex system, containing as many neurones as the spinal cord, and responsible for the coordination of normal bowel motility and secretory activities. The intrinsic innervation of the gut wall consists of two interconnected ganglionated nerve plexuses: the myenteric plexus (located between longitudinal and circular muscle coats) and the submucous plexus, which extend from the oesophagus to the anus without interruption. The intrinsic plexuses collectively innervate the mucosa, muscle layers and blood vessels of the gut, and contain reflex pathways which mediate such activities as peristalsis. The extrinsic innervation of the gut wall comprises parasympathetic and sensory nerves: disruption of this supply produces little or no impairment of function in large or small bowel..$^{13-15} \mathrm{~A}$ few nerve fibres are detectable in the lamina propria and muscularis mucosae of the normal rec- tum and colon, and ganglionic neurones can be seen in the muscularis mucosae.

\section{Development of the enteric nervous system}

It is probable that in humans, as in chicken, rabbit and mouse, all enteric neurones are derived from the neural crest. ${ }^{15}{ }^{16}$ Neural crest stem cells arise in the dorsal neural tube. They are similar to haemopoietic stem cells, in that they divide and seem to give rise to committed, multipotential progenitors, which divide further to give rise to differentiated cells. This process is influenced both by their site of origin in the neural tube and by the environment into which they migrate. Enteric neural crest cells originate from two distinct levels of the neural tube: the vagal and sacral regions. Vagal progenitors of the ENS leave the dorsal neural tube, at around the 10 somite stage (approximately three weeks' gestation in humans), and migrate through the mesoderm into branchial arch IV. From here, they course caudally through mesenchyme associated with the developing gut, and eventually coalesce in the wall of the gut where they differentiate into ganglion cells. ${ }^{15}$ In humans, neural crest derived cells first appear in the oesophagus at about four weeks' gestation, and the myenteric plexus is formed by week $12 .^{18}$

The distal (post-umbilical) ENS was previously thought to be derived exclusively from sacral neural crest. However, studies using experimental quail-chick chimeras, ${ }^{16}$ neural crest ablation, ${ }^{17}$ and immunohistochemical analyses in chicken embryos ${ }^{18}$ demonstrated that the entire length of the gut is colonised by crest cells derived from the vagal region of the neural tube. Quail-chick chimeras allow the identification of cells that have emigrated from a piece of quail tissue, previously transplanted into a chicken embryo (by means of quail specific markers). In chick embryos, surgical ablation of the vagal neural crest or prevention of its cranio-caudal migration by transection of the proximal bowel, results in complete enteric aganglionosis. ${ }^{19}$ The presence of a scattering of sacrally derived neural crest cells inside the smooth muscle layer of these operated embryos suggests that either the sacral neural crest contributes only to glia, and does not differentiate into neurones, or that the differentiation of sacral crest cells into enteric neurones is dependent upon signals from vagally derived cells.

It is likely that gangliogenesis and myogenesis are independent events. In the midgut of mice, the formation of the circular muscle layer follows the appearance of the ganglia by about a day, whereas, caudal to the caecum, it precedes the differentiation of ganglion cells (D Newgreen, personal communication). The muscle forms first in the stomach, then in the rectum and subsequently in the caecum and adjacent tissues. In notable contrast, ganglia appear in a rostro-caudal sequence and become separated into two rings as the circular muscle layer forms: the presumptive myenteric and submucous plexuses.

For normal innervation of the gut to occur, neural crest cells must be able to migrate, differentiate and survive. All of these processes depend not only on the competence of the cells but also on the microenvironment in which they find themselves. There is evidence that extracellular matrix 
(ECM) components provide directional cues to migrating crest cells ${ }^{1820}$ and may also, together with neighbouring cells, provide some of the signals necessary for crest cell differentiation. In humans, the appearance of neural crest cells in the gut is preceded by expression of the ECM molecules fibronectin and hyaluronic acid, which may play a role in providing migrational cues for these cells. ${ }^{20}$ Other matrix molecules - for example, laminin and collagen type IV, have been shown to promote neurite outgrowth from settled chick enteric neurone precursors in vitro. ${ }^{17}$ Prior to terminal differentiation, crest cells may be dependent on survival factors, possibly including GDNF (glial cell line derived growth factor; see later), without which they apoptose. Cells which remain undifferentiated also probably die.

\section{Hirschsprung's disease}

Developmental neuronal dysplasias of the hindgut may be subdivided into three main categories: congenital aganglionosis (including Hirschsprung's disease), hypoganglionosis, hyperganglionosis. Hirschsprung reported two cases of chronic constipation and congenital megacolon in $1887 .{ }^{21}$ The most common clinical presentation associated with Hirschsprung's disease is colonic obstruction which presents most commonly with failure to pass meconium during the first 24 hours of life in $95 \%$ of cases. Defective autonomic control at the distal end of the gut (uncoordinated peristalsis, absence of reflex relaxation of the internal anal sphincter, weak propulsive force in the distal gut) presents as constipation alone in about $5 \%$ of cases.

Familial Hirschsprung's disease represents about $20 \%$ of cases and may be further divided into three main groups. The most common group, involving $74 \%$ of patients, is short segment disease and comprises those patients with aganglionosis as far as the rectosigmoidal junction. The second group, long segment disease, includes patients who have aganglionosis extending beyond the rectosigmoidal junction, but not involving the small bowel. In the last and most severely affected group, total colonic aganglionosis, the aganglionosis extends into the small bowel, sometimes as far as the stomach. This group accounts for $2-14 \%$ of cases, ${ }^{22}$ and can be further subdivided (see later).

The critical diagnostic feature of Hirschsprung's disease is the absence of ganglion cells in the myenteric and submucous plexuses. In addition, a network of hypertrophied ACh positive fibres can be demonstrated in full thickness or suction biopsy samples ${ }^{22}{ }^{23}$ from all patients with short and long segment Hirschsprung's disease and most of those with total colonic aganglionosis. These cholinergic fibres are thought to be extrinsic, preganglionic parasympathetic nerve fibres. Their number increases particularly in the circular muscle in the most distal aganglionic rectum, and there is a good correlation between the density of cholinergic innervation and the severity of clinical symptoms. ${ }^{15}$ The adrenergic innervation of aganglionic gut is also abnormal. Alterations in numbers of adrenergic and peptidergic nerves (vasoactive intestinal polypeptide (VIP), substance $P$, serotonin), and of extrinsic CGRP (calcitonin gene related peptide) and NPY (neuropeptide $\mathrm{Y}$ ) containing nerve fibres have been described in specimens of aganglionic bowel. It is assumed that the absence of ganglia underlies the failure of coordinated peristalsis, whereas reduction or absence of peptidergic inhibitory nerves, coupled with an increased cholinergic supply, increases uncoordinated circular muscle contraction of the distal gut. In older patients nerve fibres may also penetrate the lamina propria.

Total colonic aganglionosis can be further subdivided on the basis of the histological findings. Some cases, referred to here as group A, are histologically similar to short segment and long segment disease. In other cases (group
B), however, there is an absence of ganglia, but little, or no, increase in the number of nerve fibres observed, a finding which can sometimes lead to a false negative diagnosis. It is tempting to speculate that the pathogenic mechanisms of short segment disease, long segment disease and group A total colonic aganglionosis may be similar, whereas the mechanism underlying group B total colonic aganglionosis may be unique.

\section{Genetics of Hirschsprung's disease}

Hirschsprung's disease is frequently familial ${ }^{1-3}$; the risk to relatives greatly exceeds the incidence in the population. It is a heterogeneous genetic disorder with dominant, recessive and polygenic forms, and a higher incidence is associated with a number of other genetic disorders including Down's syndrome. ${ }^{24}$ The clinical and pathological presentations of Hirschsprung's are variable. Moreover, occasionally patients have other developmental defects (see later). Presumably, this variability reflects the fact that there may be different, causative mutations in one or more genes, and/or incomplete penetrance of such mutations. The genetic background of the individual carrying the trait may also contribute to this variability - that is, products encoded by genetically variable genes other than the defective gene may compensate for or increase the effects of the defective gene.

Cytogenetic analyses of several families with Hirschsprung's disease have identified more than one gene defect. For example, the disease has been associated with a deletion of band $22 \mathrm{p} 22$ and a reciprocal translocation $(3 ; 7)(\mathrm{p} 21 ; \mathrm{q} 22),{ }^{25}$ a deletion in chromosome 13 (q32.3q33.2), ${ }^{26}$ and others. ${ }^{126}$ However, the types of gene defects present in a major proportion of Hirschsprung's disease families are mutations in chromosome 10q11.2, ${ }^{27} 28$ which have now been found to be associated with the proto-oncogene, ret. ${ }^{4}$ In addition, several other families with Hirschsprung's disease have an associated mutation located at chromosome $13 \mathrm{q} 22$ which is in the endothelin receptor-B (ENDR-B) gene. ${ }^{6}$

Transgenic technology, particularly in the mouse, provides a powerful method with which to produce animal models to determine the function of genes associated with human inherited disease. Both ret and ENDR-B genes have been disrupted in mice, producing phenotypes remarkably similar to Hirschsprung's disease in humans. In addition, two previously well-studied mutant mouse models of this condition, piebald lethal and lethal spotted, have been found to be due to disruptions of the ENDR-B gene ${ }^{7}$ or its ligand endothelin-3 (ET-3), ${ }^{8}$ respectively.

\section{The RET receptor tyrosine kinase}

The ret gene encodes a receptor tyrosine kinase consisting of an intracellular tyrosine kinase domain, a transmembrane domain and an extracellular domain which includes a "cadherin-like" region. ${ }^{29}{ }^{30}$ Receptor tyrosine kinases generally function as ligand dependent dimers, which phosphorylate "second messenger" proteins in the cytoplasm and they are commonly associated with regulation of cell growth and differentiation.

So far, the types of mutations found in the ret gene, which have been implicated in Hirschsprung's disease, can be placed loosely into two groups. They can be either frameshift or missense mutations which disrupt the structure of the intracellular tyrosine kinase domain ${ }^{4}$ or missense mutations in exons $2,3,5$, or 6 of the extracellular domain. ${ }^{5}$ Patients in whom mutations of the intracellular domain of ret were studied ${ }^{4}$ had either short segment or long segment type Hirschsprung's disease, and patients in whom mutations of the extracellular domain of ret were studied ${ }^{5}$ had long segment type Hirschsprung's disease (E Dow 

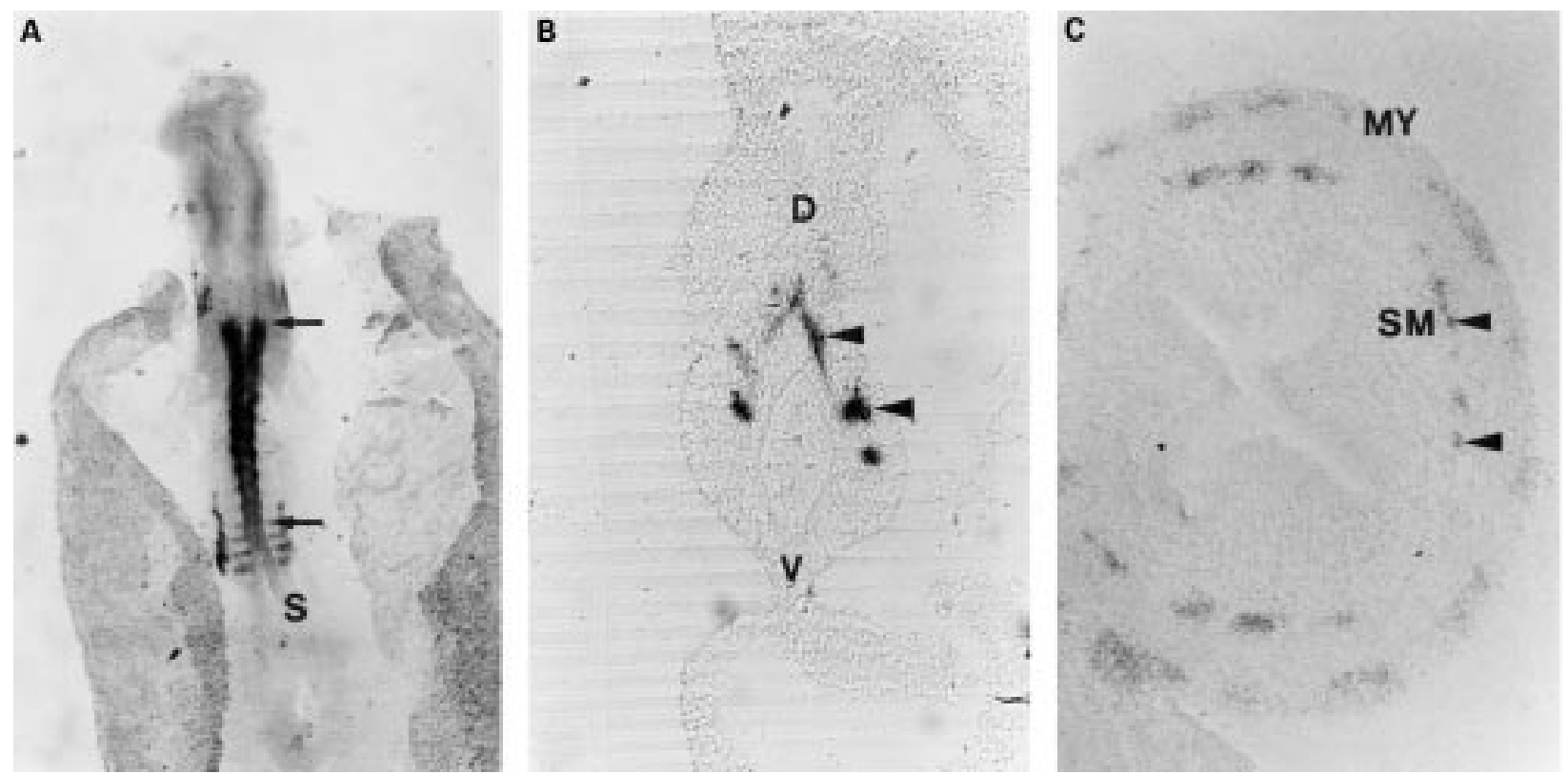

Figure 1: (A) In situ hybridisation of chicken ret to a 10 somite stage chicken embryo. ret $R N A$ is expressed in the vagal region of the neural ectoderm, (between the arrows), just prior to neural crest migration. The posterior region $(S)$ of the neural ectoderm does not express ret. (B) and (C) In situ

hybridisation of chicken ret to transverse sections through developing chicken mid-gut. (B) At embryonic day 4, ret positive neural crest derived precursors (arrowheads) are begining to migrate through the gut (D, dorsal; V, ventral). (C) At embryonic day 9, ret positive neuroblasts (arrowheads) have become organised into the myenteric (MY) and submucous (SM) plexuses. Reproduced from reference 30 with kind permission from Elsevier Science Ireland Ltd., Bay 15K, Shannon Industrial Estate, Co. Clare, Ireland.

personal communication). It is not yet known whether mutations in ret are also implicated in total colonic aganglionosis. Mutations of the tyrosine kinase domain are likely to disrupt the intracellular signalling functions of the molecule, whereas mutations in the extracellular domain may interfere with ligand binding, or impair the ability of the molecule to form functional dimers.

RET is a structurally unique receptor tyrosine kinase, having a calcium binding region, within its extracellular domain, which is homologous to that of members of the cadherin superfamily. ${ }^{29} 30$ A mutation in exon 5, which encodes the "cadherin-like" domain results in an apparent loss of function of the RET molecule, indicating that this region has an important function. Cadherins are calcium dependent, homophilic adhesion molecules ${ }^{31}$; however, the HAV motif which is associated with homophilic recognition in many cadherins, is absent from the RET sequence. ${ }^{30}$ Although the "cadherin-like" region is probably required for RET function, it is unclear exactly what it does. It may stabilise RET dimers, play a role in ligand binding, or simply modify the configuration of the dimerised molecule. In cases of Hirschsprung's disease due to a mutation in the "cadherin-like" region of RET, it has been suggested that RET functions as an adhesion molecule which is required for neural crest migration. However, there are several reasons why this is unlikely. Although some adhesion molecules are required for migration, members of the cadherin superfamily are more commonly expressed in cell aggregates. ${ }^{31}$ Moreover, RET expressing cell lines do not exhibit calcium dependent adherence ${ }^{29}$ and amino acid residues which comprise the interface for homophilic interactions between other cadherins are absent from the RET "cadherin-like" domain. ${ }^{32} 33$

The ret gene is highly conserved between different species, and is expressed during normal embryogenesis. Studies in chicken embryos show that the region of the neural tube in the embryo which gives rise to vagal neural crest expresses mRNA encoding the chicken homologue of ret prior to crest migration (fig 1A). ${ }^{30}$ Chicken ret transcripts have also been detected later in neural crest derived cells in branchial arch IV and neurone precursors in the developing gut. ${ }^{30}$ These ret positive crest cells can be seen first in the most dorsal aspect of the midgut at about 60 hours of development. They then move into the mesenchyme surrounding the gut, apparently migrating ventrally as well as caudally (fig 1B). By embryonic day 9, ret positive neurones are organised into ganglia, which are evenly spaced around the wall of the gut (fig 1C). The pattern of ret expression in the developing gut of the mouse is similar. ${ }^{34}$

In the chicken, ret mRNA is not detected in other crest cell populations at the time of their migration. ${ }^{30} \mathrm{By}$ contrast, neural crest cells which have stopped migrating, and have started to differentiate into components of the PNS, express high levels of ret, ${ }^{30}{ }^{34}$ indicating that RET is much more likely to play a role in either differentiation or survival, or both, of these cells.

\section{Aganglionosis due to loss of RET function}

$r e t-k^{-}$transgenic mice have a homozygous, targeted mutation of the tyrosine kinase domain of ret, resulting in a loss of ret function mutation. ${ }^{9}$ Neonatal ret- $k^{-}$mice accumulate milk in their stomachs indicative of defective gastrointestinal peristalsis, which correlates well with histological demonstrations of an absence of myenteric plexus neurones in the stomach and small and large intestines. ${ }^{9}$ ret- $k^{-}$mice also have a specific defect of their sympathetic nervous system-the superior cervical ganglion is missing. However, partially differentiated neurones have been demonstrated in the position of this ganglion in embryos. ${ }^{35}$ This further supports the theory that RET is not required for the migration of crest cells, but for the survival or differentiation of neuroblasts in situ.

Very recently, three groups reported that disruption of the gene which encodes glial cell line derived growth factor (GDNF) in transgenic mice resulted in the loss of several PNS components including the ENS, and kidneys. ${ }^{367}$ The remarkable similarity between this phenotype and that of the $r e t-k^{-}$mice suggested a possible functional relationship between these molecules. Indeed, two other groups 
independently identified two receptors for GDNF in ligand binding assays. One of these was RET, ${ }^{38}{ }^{39}$ the other was a novel GPI (glycosyl-phosphatidylinositol) linked protein, now called GDNFR- $\alpha$. Further studies showed that GDNF could be immunoprecipitated with anti-RET antibodies, ${ }^{40}$ and that treatment of cultured neurones with GDNF results in phosphorylation of RET. ${ }^{39}{ }^{41}$ GDNF is a potent neurotrophic factor, promoting the survival of a range of neuronal cell types in vitro. ${ }^{42}$ Its ability to promote the survival of midbrain dopaminergic neurones makes GDNF a potential therapeutic agent in the treatment of Parkinson's disease. ${ }^{43}$ Taken together, these observations strongly suggest that the function of RET is in trophic support, although this has yet to be proven. The phenotypes of the GDNF null and ret- $k^{-}$mice do not completely overlap, indicating that there may be other ligands for RET, and likewise, other receptors for GDNF (see references 32 and 33 for most recent reviews).

Occasionally, cases of Hirschsprung's disease present with additional developmental defects - for example, congenital deafness, renal agenesis and abnormalities of the facial skeleton. ${ }^{24}{ }^{44}$ Interestingly, the primordia of all of the tissues affected in these syndromes express ret transcripts during their development. ${ }^{30}{ }^{34}$ In chicken embryos, ret is expressed in the otic vesicles, ${ }^{30}$ and both in mice and chickens, it is expressed in the mesonephros and cranial neural crest. ${ }^{30}{ }^{34}$ In mice, ret is expressed in the ureteric bud of the developing kidney, and is thought to play a role in the growth and development of the structures that are derived from it-namely, the collecting ducts, papillae and calyces. ${ }^{34}$ Renal agenesis is one of the defects of ret- $k^{-}$ transgenic mice. ${ }^{9}$

However, defects in the kidney or superior cervical ganglion are rare in humans with Hirschsprung's disease. Mutations associated with Hirschsprung's disease are autosomal dominant resulting in haploinsufficiency of functional RET, whereas the ret- $k^{-}$transgenic mouse shows no defects when heterozygous for the mutant allele. It is very likely that homozygosity for loss of RET function would be embryonic lethal in humans due to the prenatal requirement for kidney function. In addition, although it is surprising that the heterozygous mutant mouse does not show the ENS defects associated with the heterozygous human condition, this may simply reflect a difference in protein dosage requirements between the two species.

\section{Endothelin-3 and its receptor in aganglionosis}

In the same year as the connection between mutations in the RET receptor and a subset of familial Hirschsprung's lineages was established, mutations in a different cell surface receptor, ENDR-B and its ligand, endothelin-3 (ET-3), were also implicated in the disease. ${ }^{6-8}$ The endothelin peptide family of secreted peptides comprises four members to date: ET-1, ET-2, ET-3, and VIP. They transduce a signal via two cell surface transmembrane receptors: ENDR-B, which binds all four ligands, and ENDR-A, which binds only to ET- $1 .^{7}$ ENDRs are G-protein coupled receptors which, when activated by a ligand, induce a calcium flux into the cell. ${ }^{6}$ In human fetuses, both ENDR-B and ET- 3 have been demonstrated on enteric neurones and gut mesenchyme cells, suggesting that the function of ET-3 and ENDR-B may be to regulate interactions between neural crest cells and gut mesenchyme cells, necessary for normal migration. As previously described for ret, mice with defects in the ET-3 or ENDR-B genes also offer the prospect of considerably improving our understanding of the human condition.
ENDOTHELIN-3 AND THE LETHAL SPOTTED MOUSE MUTANT Lethal spotted (ls/ls) mutant mice have congenital aganglionosis, in which the proximal region of the bowel contains fully differentiated ganglion cells, but the distal region of the colon is aganglionic. ${ }^{45} l s / l s$ is a result of the expression of a recessive mutation on mouse chromosome 2: homozygotes have a $100 \%$ incidence of aganglionosis. ${ }^{46}$ The $l s / l s$ associated mutation has been identified as a mutation in the ET-3 gene which prevents the cleavage of inactive ET-3 precursor into the active peptide. ${ }^{8}$

As in Hirschsprung's disease, the rectum of $l s / l s$ mice contains numerous extrinsic nerve fibres, and hypertrophic smooth muscle cells. ${ }^{47}$ In $l s / l s$ embryos, it seems that neural crest cells fail to colonise the terminal bowel, and it has been assumed that the pathology reflects a failure of migration of neural crest cells. However, crest cells in these mice are capable of some migration, and of differentiation into neurones, if they are co-cultured with rectal segments from normal embryos. ${ }^{45}$ Moreover, if crest cells from normal mice are co-cultured with bowel segments from $l s / l s$ mice, they fail to colonise the segments adequately. ${ }^{45}$ Failure to colonise the bowel may therefore reflect abnormalities of the enteric environment including the ECM. Abnormal distributions of ECM proteins such as collagen type II, glycosaminoglycans (GAGs) and laminin have been demonstrated in the mucosa of the terminal gut in $l s / l s$ mice as early as embryonic day 11 , a time which precedes the appearance of enteric neurones in normal mice. ${ }^{45}$ The excessive accumulation of GAGs, which persists until birth, occurs exclusively in the aganglionic regions, and may be non-permissive to cell movement.

In order to investigate the cellular mechanisms underlying $l s / l s$ further, Kapur et al made a transgene, D $\beta \mathrm{H}-n l a c Z$, which uses the promoter region of dopamine $\beta$-hydroxylase (a marker for enteric neuroblasts) to drive tissue specific expression of $\beta$-galactosidase. ${ }^{10}$ The neuroblasts can subsequently be identified in tissue sections by the addition of X-gal substrate, which reacts with $\beta$-galactosidase to give a blue product. By putting the transgene into $l s / l s$ mice it was confirmed that the defect is due to a failure of colonisation of distal gut by enteric neuroblasts and not a failure of neuroblast differentiation preceded by normal neuroblast migration.

$l s / l s$ mice also have an additional defect, of melanogenesis, which results in white spotting in coat colour. ${ }^{46}$ Melanocytes are also neural crest derivatives. As there is some pigmentation in the skin of these mice, melanocytes can obviously differentiate, strongly suggesting that this defect may arise because the melanoblasts fail to migrate adequately through the skin.

ENDR-B AND THE PIEBALD LETHAL MUTANT MOUSE

A mutation associated with Hirschsprung's disease in several families on chromosome $13 \mathrm{q} 22$ is in the ENDR-B gene. ${ }^{6}$ In humans the mutation is in exon 4 and replaces a Trp residue with a Cys in the fifth transmembrane domain. This substitution may disrupt the signalling properties of ENDR-B, as the mutant ENDR-B gene product is unable to alter cellular calcium concentrations. ${ }^{6}$ The q22 region of human chromosome 13 is syntenic with part of mouse chromosome 14. In the mouse, a mutation (piebald lethal; $s^{\prime}$ ) mapping to the region of synteny causes megacolon and white spotting in coat colour, ${ }^{6}$ a phenotype identical to lethal spotted (see earlier). This mutation has recently been shown to be a complete deletion of the ENDR-B gene. ${ }^{7}$ Moreover, a transgenic mouse, ENDRB-null, with a mutation targeted to the ENDR-B gene, has a phenotype identical to piebald lethal. ${ }^{7}$

Bearing in mind that ENDR-B is the receptor for ET-3, it is reasonable to assume that the defect in $s^{\prime} / s^{\prime}$ is also due 
to a failure of migration of neuroblasts into the terminal bowel. Again, it is not clear whether the crest cells themselves are defective, or whether the gut mesenchyme is non-permissive to their migration. This problem has been investigated in chimeric mice made from transgenic $\mathrm{D} \beta \mathrm{H}-$ $n l a c Z-s^{\prime} / s^{\prime}$ mice and wild type (unaffected) mice. ${ }^{11}$ In the chimeric embryos, $50 \%$ of the enteric neuroblast population would be expected to carry the $s^{\prime} / s^{\prime}$ mutation and $\beta$-galactosidase. The other $50 \%$ would be normal cells. If the $s^{\prime} / s^{\prime}$ defect is neuroblast autonomous, there should be no Lac- $Z$ carrying cells in the distal gut. In fact, in many embryos there were Lac- $Z$ positive cells in the distal gut. ${ }^{11}$ The number of Lac- $Z$ positive cells that had migrated into the distal gut was variable, but constituted up to $55 \%$ of the neurone population. Clearly, the wild type cells were able to rescue the mutant cells, which may indicate a requirement for intercellular signals, downstream of ET-3, to mediate colonisation. One model which could explain these findings is that the endothelins have an autocrine effect. $s^{\prime} / s^{\prime}$ cells may express ENDR-A, which is activated by ET-1. Activation of ENDR-A may result in the production of one, or all, of the other endothelins, which can all bind to ENDR-B. Activation of ENDR-B may also result in upregulation of secretion of the endothelins, thereby amplifying their effects. In the absence of ENDR-B, there would be no amplification step, and the total amount of endothelin produced would be too small to initiate migration. In the chimeric animals, the wild type cells may express enough ENDR-B to rescue this amplification step or the mutant cells, or both. What is not clear is whether these downstream signals are provided by wild type gut mesenchyme or neuroblasts, or both.

\section{Surgically generated experimental models of Hirschsprung's disease}

Most surgically generated experimental models, as opposed to genetic models, for Hirschsprung's disease are made in chicken embryos, which are easily accessible, and in which development of the ENS has been well documented. There are no chicken strains with spontaneous aganglionosis, but aganglionosis can be induced by surgical ablation of premigratory neural crest. ${ }^{18}$ Although this procedure tells us nothing about the mechanism of Hirschsprung's disease, it can be used to investigate possible treatment strategies. For example, it is possible both in chickens $^{48}{ }^{49}$ and mice ${ }^{45}$ to re-colonise aganglionic bowel with neural crest cells by transplanting tissue obtained from the dorsal neural tube. It has also been shown that neurones from more proximal regions of bowel, if taken at early stages after their differentiation, are very plastic, and are capable of re-colonising distal bowel and forming enteric ganglia. ${ }^{49}{ }^{50}$ Such transplant strategies may one day be possible in humans.

\section{Management and treatment of Hirschsprung's disease}

The ability to determine the presence of relevant gene mutations in material acquired by amniocentesis may prove to be enormously advantageous for the management of Hirschsprung's disease. The majority of cases are diagnosed within three months of birth, although sometimes diagnosis occurs only after there are secondary complications, such as gut dilatation caused by obstruction, infection, or occasionally a ruptured caecum. Firm antenatal diagnosis, especially in early pregnancy in families with previously affected children, would mean that treatment could be instigated before the onset of complications.

It is clear that there is a need to understand the development of the ENS in greater clarity than at present. It is not known at what stage enteric neurones lose their plasticity. Nor is it known at what stage the preganglionic parasympathetic fibres form synapses with enteric ganglia, or whether they would subsequently be capable of forming synapses with artificially introduced neurones. The animal models described earlier may provide answers to these, and other, questions.

We thank Professor B Lake, Institute of Child Health, London, and Dr E Dow, St Mary's Hospital, London, for invaluable advice and discussion, Ms Sarah St Mary's Hospital, London, for invaluable advice and discussion, Ms Sarah
Smith for photomicrography and Dr M B Taylor for his helpful comments on Smith for photomicrography and $\mathrm{Dr} M \mathrm{M}$ B Taylor for his helpful comments on
the manuscript. Work in the authors' laboratories is funded by awards from the the manuscript. Work in the authors' laboratories is funded by awards from the
Wellcome Trust (IM, SH), MRC (IM), Special Trustees of Guy's Hospital Wellcome Trust (IM, SH), MRC (IM), Special Tru
(SH), and Human Frontier Science Programme (IM).

K ROBERTSON I MASON

MRC Brain Development Programme,

Department of Developmental Neurobiology,

UMDS Guy's Hospital,

London SE1 9RT, UK

Department of Anatomy and Cell Biology

S HALL

Correspondence to: Dr K Robertson, Department of Neurobiology, University of Pittsburgh School of Medicine, E1446 Biomedical Science Tower, Pittsburgh, PA 15261, USA.

Badner JA, Sieber WK, Garver KL, Chakravarti A. A genetic study of Hirschsprung's disease. Am f Hum Genet 1990; 46: 568-80.

Garver KL, Law JC, Garver B. Hirschsprung's disease; a genetic study. Clin Genet 1985; 28: 503-8.

3 Passarge E. The genetics of Hirschprung's disease: evidence for a heterogeneous etiology and a study of sixty-three families. $N$ Engl f Med 1967; 276: $138-43$.

4 Romeo G, Ronchetto P, Luo Y, Barone V, Seri M, Ceccherini I, et al. Point mutations affecting the tyrosine kinase domain of the RET proto-oncogene in Hirschsprung's disease. Nature 1994; 367: 377-8.

5 Edery P, Lyonnet S, Mulligan LM, Pelet A, Dow E, Abel L, et al. Mutations of the RET proto-oncogene in Hirschsprung's disease. Nature 1994; 367: of the R $378-80$.

6 Puffenberger EG, Hosoda K, Washington SS, Nakao K, de Wit D, Yanagisawana $M$, et al. A missense mutation of the endothelin-B receptor gene in multigenic Hirschsprung's disease. Cell 1994; 79: 1257-66.

7 Hosoda K, Hammer RE, Richardson JA, Baynesh AG, Cheung JC, Giaida $\mathrm{A}$, et al. Targeted and natural (piebald-lethal) mutatations of endothelin-b receptor gene produce megacolon associated with spotted coat colour in mice. Cell 1994; 79: 1267-76.

8 Baynash AG, Hosoda K, Giaida A. Interaction of endothelin 3 with the endothelin B receptor is essential for development of neural crest-derived melanocytes and enteric neurons: missense mutation in endothelin 3 gene in lethal spotting mice. Cell 1994; 79: 1277-85.

9 Schuchardt A, D'Agati V, Larsson-Blomberg L Costantini F, Pachnis V. Defects in the kidney and enteric nervous system of mice lacking the tyrosine kinase receptor RET. Nature 1994;367: 380-3.

10 Kapur RP, Yost C, Palmiter RD. A transgenic model for studying the development of the enteric nervous system in normal and aganglionic mice. opment of the enteric nervous

11 Kapur RP, Sweetser DA, Doggett B, Siebert JR, Palmiter RD. Intercellular signals downstream of endothelin receptor-B mediate colonisation of the large intestine by enteric neuroblasts. Development 1995; 121: 3787-95.

12 Langley JN: The autonomic nervous system. Part 1. Cambridge: Heffer, 1921.

13 Furness JB, Costa M. The enteric nervous system. Edinburgh: Churchill Livingstone, 1987.

14 Burnstock G. Innervation of bladder and bowel. Neurobiology of incontinence. Ciba Found Symp 1990; 151: 2-26.

15 Heaton ND, Garrett JR, Howard ER. The enteric nervous system: structure and pathology. In: Autonomic failure. A textbook of clinical disorders of the autonomic nervous system. 2nd edn. Oxford: Oxford University Press, 1988: $238-48$

16 Le Douarin NM, Teillet MA. The migration of neural crest cells to the wall of the digestive tract. F Embryol Exp Morphol 1973; 30: 31-48.

17 Yntema CL, Hammond WS. The origin of intrinsic ganglia of trunk viscera from vagal neural crest in the chicken embryo. F Comp Neurol 1954; 101: 515-41.

18 Carel Meijers JH, Tibboel D, van der Kamp A, van Harperen-Heuts IC. A model for aganglionosis in the chicken embryo. F Pediatr Surg 1989; 6: 557-61.

19 Pomeranz HD, Gershon MD. Colonisation of the avian hindgut by cells derived from the sacral neural crest. Dev Biol 1990; 137: 378-94.

20 Fujimoto T, Hata J, Yokoyama S, Mitomi T. A study of the extracellular matrix protein as the migration pathway of neural crest cells in the gut: Analysis in human embryos with special reference to the pathogenesis of Hirschsprung's disease. F Pediatr Surg 1989; 24: 550-6.

21 Hirschsprung $\mathrm{H}$. Stuhltragheit Neugeborener in folge von dilatation und hypertrophie des colons. Fahrbuch Kinderheilk 1887; 27: 1-7.

22 Lake BD. Hirschsprung's disease and pseudo-obstruction. In: Phillipe I, ed. Histochemistry in pathology. Edinburgh: Churchill Livingstone, 1990: 211-20

23 Gannon BJ, Burnstock G, Noblett H, Campbell PE. Histochemical diagnosis of Hirschsprung's disease. Lancet. 1969; i: 894-5.

24 Halal F, Morel J. The syndrome of Hirschsprung's disease, microcephaly, unusual face, and mental retardation. Am f Med Genet 1990; 37: 106-8.

25 Webb GC, Keith CG, Campbell NT. Concurrent de novo interstitial deletion of band $2 \mathrm{p} 22$ and reciprocal translocation $(3 ; 7)(\mathrm{p} 21 ; \mathrm{q} 22) . \mathcal{F}$ Med Genet 1988; 25: 125-7. 
26 Bottani A, Xie Y, Binkert F, Schnizel A. A case of Hirschsprung's disease with a chromosome 13 microdeletion, del(13)(q32.3q33.2): potential
mapping of one disease locus. Hum Genet 1991; 87: 748-50.

27 Angrist M, Kauffman E, Slaugenhaupt SA, Matise TC, Puffenberger EG, Washington SS. A gene for Hirschsprung's disease (mega-colon) in the pericentromeric region of human chromosome 10. Nat Genet 1993; 4: 351-6.

28 Lyonnet S, Bolono A, Pelet A, Abel L, Nihoul-Fekete C, Briaird ML, et al. A gene for Hirschsprung's disease maps to the proximal long arm of chromosome 10. Nat Genet 1993; 4: 346-50.

29 Iwamoto T, Taniguchi M, Asai N, Ohkusus K, Nakashima I, Takahashi M. cDNA cloning of mouse RET proto-oncogene and its sequence similarity to the cadherin superfamily. Oncogene 1993; 8: 1087-91.

30 Robertson K, Mason IJ. Expression of ret in the chicken embryo suggests roles in regionalisation of the vagal neural tube and somites and in the development of multiple neural crest and placodal lineages. Mech Dev 1995; 53: 329-44.

31 Pouliot Y. Phylogenetic analysis of the cadherin superfamily. BioEssays 1992; 14: 743-8.

32 Mason I. The GDNF receptor: recent progress and unanswered questions. Mol Cell Neurosci 1996; 8: 112-9.

33 Robertson K, Mason I. The GDNF-RET signalling partnership. Trends Genet 1997; 13: 1-3.

34 Pachnis V, Mankoo B, Costantini F. Expression of the c-ret proto-oncogene during mouse embryogenesis. Development 1994; 119: 1005-17.

35 Durbec P, Larsson-Blomberg LB, Schuchardt A, Costantini F, Pachnis V. Common origin and developmental dependence on c-ret subsets of enteric and sympathetic neuroblasts. Development 1996; 122: 349-58.

36 Moore MW, Klein RD, Farinas I, Sauer H, Armanini M, Phillips H, et al. Renal and neuronal abnormalities in mice lacking GDNF. Nature 1996; 382: $76-9$.

37 Pichel JG, Shen L, Sheng HZ, Granholm AC, Drago J, Grinbeg A, et al. Defects in enteric innervation and kidney development in mice lacking GDNF. Nature. 1996; 382: 73-6.

38 Sanchez MP, Silos-Santiago I, Frisen J, He B, Lira SA, Barbacid M. Renal agenesis and the absence of enteric neurons in mice lacking GDNF. Nature 1996; 382: 70-2.
39 Jing S, Wen D, Yu Y, Holst PL, Luo Y, Fang M, et al. GDNF induced actiJing $\mathrm{S}$, Wen $\mathrm{D}$, Yu Y, Holst PL, Luo Y, Fang M, et al. GDNF induced acti-
vation of the Ret protein tyrosine kinase is mediated by GDNFR- $\alpha$, a novel receptor for GDNF. Cell 1996; 85: 1113-24.

40 Treanor JJS, Goodman L, de Sauvage F, Stone DM, Poulsen CT, Beck CD, et al. Characterisation of a multicompetent receptor for GDNF. Nature. 1996; 382: 80-83.

41 Trupp M, Arenas E, Fainzibler M, Nilsson AS, Sieber BA, Grigoriou M, et al. Peripheral expression and biological activities of GDNF, a new neurotrophic factor for avian and mammalian peripheral neurons. Nature 1996; 381: 789-93.

42 Buj-Bello A, Buchman VL, Horton A, Rosenthal A, Davies AM. GDNF is an age specific survival factor of sensory and autonomic neurons. Neuron 1995; 15: 821-8.

43 Lin LF, Doherty DH, Lile JD, Bektesh S, Collins F. GDNF: a glial cell line derived neurotrophic factor for midbrain dopaminergic neurons. Science 1993; 260: 1130-2.

44 Santos H, Mateus J, Leal MJ. Hirschsprung's disease associated with polydactyly, unilateral renal agenesis, hypertolorism, and congenital deafness: a new autosomal recessive syndrome. F Med Genet 1988; 25: 204-8.

45 Payette RF, Tennyson VM, Pomeranz HD, Pham TD, Rothman TP, Gershon MD, et al. Accumulation of components of basal laminae: association with the failure of neural crest cells to colonise the presumptive aganglionic bowel of 1s/1s mutant mice. Dev Biol 1988; 125: 341-60.

46 Wolfe H, Coleman D. Pigmentation. In: Green EL, ed. Biology of the laboratory mouse. New York: Dover, 1966: 405-25.

47 Tennyson V, Pham T, Rothman T, Gershon MD. Abnormalities of smooth muscle, basal laminae and nerves in the aganglionic segments of bowel of lethal spotted mutant mice. Anat Rec 1986; 215: 267-81

48 Gershon MD, Chalazonitis A, Rothman TP. From neural crest to bowel: development of the enteric nervous system. F Neurobiol 1993; 24: 199-214.

49 Rothman TP, Le Douarin NM, Fontaine-Perus JC, Gershon MD. Developmental potential of neural crest derived cells migrating from segments of developing quail bowel back grafted into younger chick host embryos. Development 1990; 119: 411-23.

50 Theiry JP, Duband JL, Delovee A. Pathways and mechanisms of avian trunk neural crest migration and localisation. Dev Biol 1982; 93: 324-43. 